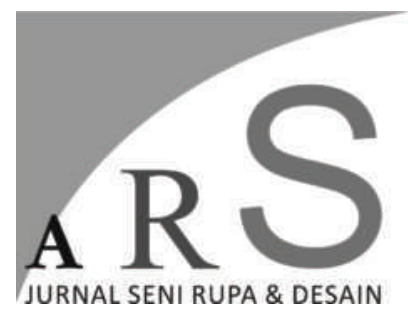

Volume 21 Nomor 3 - Desember 2018

\title{
PENDEKATAN TEORI KOMIK PADA ADEGAN RELIEF KRESNAYANA CANDI WISNU
}

\author{
Yohanes Sambodo \\ Program Studi Seni Rupa Murni, Jurusan Seni Murni \\ Fakultas Seni Rupa, Institut Seni Indonesia Yogyakarta
}

\begin{abstract}
ABSTRAK
Penelitian ini mengetengahkan pengidentifikasian unsur-unsur komik yang terdapat pada relief tersebut menggunakan teori komik. Berbagai unsur dalam komik dapat dipelajari dari teori yang ditulis oleh Scott McCloud. Memang tidak semua unsur komik terdapat pada relief itu, khususnya disebabkan oleh medianya. Beberapa unsur yang terpenting di antaranya adalah panel, pertokohan dan transisi antarpanel. Unsur komik lainnya juga dapat digunakan untuk membedah relief Kresnayana, kecuali yang termasuk kata-kata. Sebagai hasilnya, relief Kresnayana dan komik menunjukkan adanya beberapa kesamaan maupun ketidaksamaan dalam unsur-unsurnya. Semua panelnya ternyata merupakan gabungan pecahan-pecahan batu. Kemudian, parit (gutter) dalam relief ini juga unik, yaitu berupa dua pilar yang mengapit panel. Transisi antarpanel dalam relief Kresnayana berpatokan pada cara pradaksina.
\end{abstract}

Kata Kunci: komik, relief Kresnayana, panel, parit, transisi antar panel

\begin{abstract}
The research is set forth about the identification of comic elements that contained in the reliefs using comic theories. Various comic elements could be learned as theories wrote by Scott McCloud. It is not likely all the elements could be found in it though, mainly caused by two different medium. Only couple can become essential such as panels, characters and interpanel transition. The other elements of comic are also useful for examining the object, except any part of words. As the results, Kresnayana reliefs and comic are indicates some similarities as well as dissimilarities in their elements. A panel is completely joint up from square stone pieces. Also, the gutter is unique, it is shown with two columns that enclose both of the panel sides. The panel transition on the Kresnayana relief is following the standard as the way of pradaksina.
\end{abstract}

Keywords: comic, Kresnayana relief, panel, gutter, interpanel transition 


\section{Pendahuluan}

\section{Latar Belakang Penelitian}

Kemunculan komik di Indonesia dipicu oleh beredarnya komik-komik dari luar negeri. Dalam perkembangannya, komik dari Amerika dan Cina mendominasi penerbitan dan peredaran komik di Indonesia pada tahun 1930-an, dan pada tahun 1980-an, booming komik domestik mampu bertahan di tanah air. Secara visual komik yang berkembang di Indonesia figur-figurnya komunikatif, baik visual maupun narasinya terkesan populer sehingga mudah diterima pada waktu itu.

Sifat komik yang demikian akhirnya dapat diterima oleh masyarakat meskipun awalnya dalam bahasa asing dan muncul dalam media massa masih berbentukstrip (komik bersambung). Put On adalah komik strip pertama yang diterbitkan melalui surat kabar Sin Po pada tahun 1930 di Indonesia (Bonneff, 1998: 19), disusul dengan penerbitan komik-komik lokal yang tidak kalah menarik dengan kehadiran pendekar, wayang atau superhero lokal. Banyak faktor yang memengaruhi laju perkembangan komik Indonesia setelahnya, termasuk salah satunya faktor budaya baca masyarakat yang meningkat dan munculnya percetakan-percetakan.

Komik adalah hasil kebudayaan impor dari luar negeri yang selanjutnya menjadi tren. Di Indonesia, komik pun telah masuk dalam wilayah akademis, melalui penelitian-penelitian yang dilakukan di dalam kampus. Penelitian mengetengahkan anatomi dan kebentukan dalam banyak karakter tokohnya, bahkan budaya tersebut dapat diacu untuk meneliti struktur pada artefak budaya yang ada di Indonesia. Artefak budaya Indonesia seperti Candi Borobudur atau Prambanan, Wayang Beber dan Wayang Kulit; dapat dianggap sebagai cikal bakal komik dalam negeri. (Bonneff, 1998)

Pada dasarnya, komik tidak harus berwujud buku. Hal ini telah dikatakan oleh Marcell Bonneff bahwa relief candi pun dapat dikategorikan salah satu bentuk dari komik. (Bonneff, 1998: 17) Secara umum, dalam komik terdapat tulisan yang bisa langsung dibaca sedangkan relief membutuhkan seorang pemandu/penerjemah cerita relief itu sendiri. Berhubungan dengan hal penerjemahan, relief juga dikatakan mengandung unsur atau struktur seperti panel dan urutannya. Unsur ini dapat diterjemahkan dengan suatu pendekatan yang mendukung. Ini merupakan satu hal yang menarik, bahwa struktur visual relief dapat diamati, diteliti dan dikaitkan seperti struktur visual yang ada dalam komik modern.

Relief Candi Wisnu memiliki potensi dalam kajian teori komik. Mengenai relief yang akan diteliti, perlu diketahui bahwa lokasinya berada di wilayah Yogyakarta. Relief ini berada di Candi Wisnu dalam sekompleks Candi Roro Jonggrang di Prambanan. Di Candi Wisnu tersebut terdapat relief Kresnayana yang mengisahkan dewa yang menjelma menjadi manusia. Relief kisah Kresnayana akan dipilih sebagai objek penelitian karena masih dapat dilacak keberadaannya. Relief kisah ini belum begitu dikenal sebagaimana kisah Ramayana . Namun, buku yang membahas tentang relief tersebut sudah ada, berjudul "The Kresnayana Reliefs of The Visnu Temple”. Dalam buku itu terdapat foto-foto relief pada Candi Wisnu. Setiap foto relief ada keterangan tentang adegannya. Detil cerita tentang Kresnayana dapat disimak pada setiap panel adegan dalam buku tersebut.

Aspek visual cerita Kresnayana akan dikupas dengan pendekatan teori komik milik Scott McCloud. (1993) Apa yang dilakukan dalam penelitian ini menjadi menarik dengan "menyatukan" antara artefak klasik dengan teori modern komik.

\section{Rumusan Masalah dan Tujuan Penelitian}

Unsur-unsur komik ada banyak, namun jika digunakan untuk membahas relief Kresnayana belum tentu bisa dikaitkan semuanya. Sebab tidak semua unsur komik dapat diterapkan dalam relief. Berlandaskan itu, teori komik Scott McCloud akan dipilah dan dipilih sesuai relevansi. Selanjutnya, akan digunakan untuk mengidentifikasi unsur-unsur komik yang terdapat pada relief Kresnayana. Dengan perumusan di atas, maka tujuan yang spesifik adalah agar dapat mengidentifikasi teori dan unsur-unsur komik pada relief Kresnayana di Candi Wisnu. 


\section{Landasan Teori}

Relief termasuk seni patung yang menampilkan gambar semi tiga dimensional. Objek-objeknya dibuat menonjol lebih ke muka dan masih menyertakan bagian alasnya di belakang. Relief naratif yang ada di Candi Wisnu Prambanan jenisnya bas relief. Relief semacam ini mengurangi $1 / 2$ sampai $3 / 4$ dari ketebalan batu untuk menonjolkan objek-objeknya ke muka sehingga terdapat relung-relung yang cukup dalam.

Komik dan relief dapat disebut sebuah wujud teks. Keduanya dapat berfungsi untuk menerangkan informasi kepada pembaca dengan kandungan estetisnya masing-masing. Pembaca dapat menentukan sendiri cara untuk menyerap informasinya. Relief narasi digunakan untuk menggambarkan suatu kisah yang secara verbal dilakukan oleh seorang pemandunya. Komik dapat lebih komplit karena selain terdapat gambar, tampak pula kata-kata yang tertulis. Relief di Candi Wisnu menceritakan sebuah kisah. Kisah ini disebut Kresnayana, sehingga disebut Relief Kresnayana. Secara umum, relief Kresnayana ini mengisahkan masa sebelum Kresna turun ke dunia; masa kanak-kanak, masa remaja dan masa dewasa Kresna (Moertjipto \& Prasetya, 1997:12)

Dewa Wisnu dalam kitab Bhagawatapurana mempunyai banyak avatara, namun yang dikenal luas hanya ada 10 avatara. Dari kesepuluh avatara, salah satunya adalah Kresna avatara. Oleh karena dewa Wisnu adalah pemelihara bumi, maka Ia turun ke bumi pada saat bumi terancam bahaya dari kekuatan jahat. Wisnu berinkarnasi menjadi manusia dan menyelamatkan bumi. Dalam cerita Kresnayana, dewa Wisnu menjelma menjadi Kresna yang berjuang menumpas kejahatan yang dikuasai oleh tokoh yang bernama Kamsa dan Yawana. Ia dibantu oleh saudara laki-lakinya yang disebut Balarama. Dalam kaitannya dengan komik, relief Kresnayana diwujudkan dalam panel-panel. Dalam pandangan Scott McCloud, panel merupakan suatu unsur yang penting. Panel dalam komik berfungsi sebagai ruang penyimpan suatu adegan. Hal ini berhubungan dengan penggambaran ruang dan waktu. Ruang dan waktu dalam komik dapat diukur oleh sebuah panel saja ataupun lebih. Satu panel menampung satu adegan yang difragmentasi, jadi bersifat penggalan atau cuplikan.
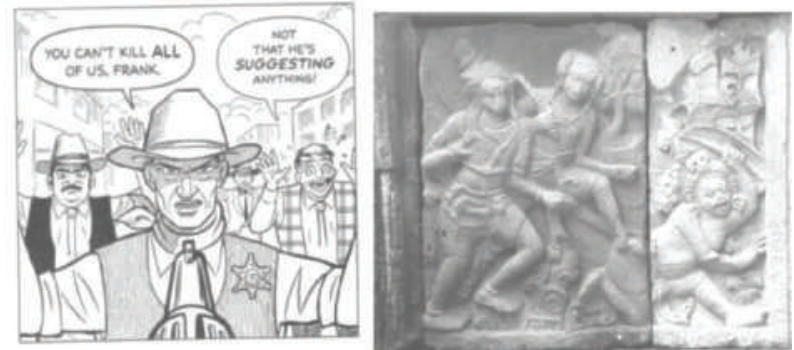

Gb. 1. Persamaan panel komik dengan relief (Sumber gambar: Scott McCloud dan dokumentasi Yohanes Sambodo)

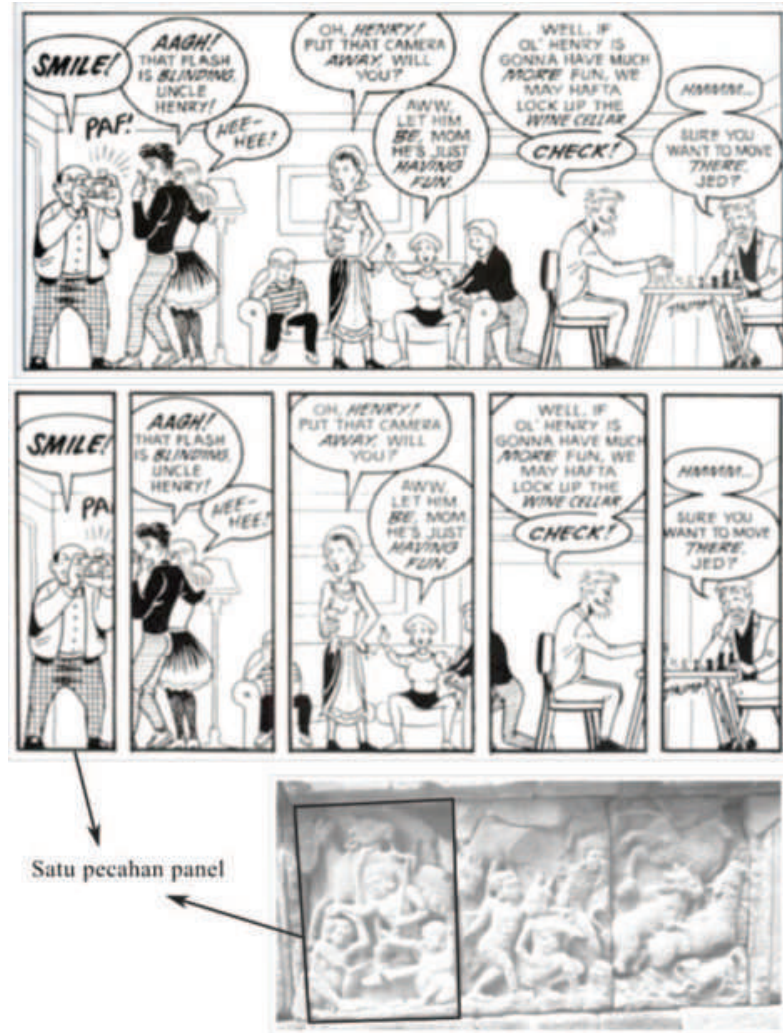

Gb. 2. Satu panel yang dapat terbagi dalam beberapa pecahan panel

(Sumber gambar: Scott McCloud dan dokumentasi

Yohanes Sambodo)

Panel yang berturutan akan menghasilkan rangkaian waktu yang terlihat lewat adeganadegannya. Melihat panel pertama adalah saat ini, panel selanjutnya sudah berganti waktu atau merujuk pada transisinya. Penggambaran satu panel dengan banyak adegan di dalamnya akan terasa kompleks untuk dibaca, dikarenakan 
masing-masing objek memiliki waktunya sendiri. Namun, apabila satu panel itu dibagi menjadi panel-panel atau pecahan yang lebih kecil, maka dapat meringankan maksud turutannya. Satu panel dapat bekerja sebagai beberapa panel. (McCloud, 1993: 97) Hal ini seperti pada relief yang pecahan-pecahan di dalam satu panel saling bersandingan.

Satu panel berisi gambar tanpa kata-kata bukan komik, kecuali panel-panel bergambar itu memiliki perbedaan yang berhubungan dan saling bersebelahan, berdekatan. Disamping itu, Scott juga mendefinisikan komik sebagai seni berturutan; yaitu gambar-gambar serta lambanglambang lain yang terjukstaposisi (bersebelahan dan berturutan) dalam turutan tertentu. (McCloud, 1993:9)

Komik yang lengkap berisi banyak panel, oleh sebab itu rangkaian panelnya menunjukkan transisi antarpanel. Transisi antarpanel meliputi:

a. Momen ke momen, transisi secara berturutan yang menampilkan sangat sedikit pergeseran waktu. Seperti pemotretan yang sangat lambat.

b. Aksi ke aksi, penggambaran satu tokoh yang melakukan urutan aksi tertentu dan berkaitan jelas.

c. Subjek ke subjek, objek dalam panelpanelnya dikhususkan untuk lebih dari satu figur (benda hidup atau mati) yang saling berinteraksi.

d. Adegan ke adegan, transisi untuk menggambarkan perubahan ruang dan waktu yang cukup drastis. Unsur konten antarpanelnya biasanya berbeda jauh.

e. Aspek ke aspek, perwujudan urutan panel yang berisi suasana atau topik tertentu dan sensasional.

f. Transisi tak berhubungan (Non-sequitur), transisi yang tanpa ada hubungan sedikitpun. Kontennya berubah sangat drastis, baik objek maupun plotnya, namun hubungannya dapat diimajinasikan.

Selain panel, unsur komik yang dapat disesuaikan di sini adalah closure, sudut pandang dan pertokohan. Pada panel, closure dihadirkan untuk menunjukkan kepada pembaca akan potongan bagian suatu gambar. Pada parit, closure dapat dipakai untuk menimbulkan rasa penasaran dan interpretasi yang dinamis kepada pembaca. Disini perlu diketahui pula arah dalam membaca komik yang umumnya dibaca dari kiri atas ke kanan bawah. Closure parit antarpanel memang tidak mudah untuk dibuat oleh kreator dan "ditangkap" oleh pembaca. Imajinasi pembaca akan dibutuhkan sekali dalam mencermati closure-closure pada komik, terlebih pada parit.

Sudut pandang dalam komik mirip seperti sudut pandang pada pemotretan dengan kamera. Variasi sudut pandang dalam pemotretan dapat diterapkan dalam komik. Panel dalam komik bisa disebut sebagai kamera-nya pembaca. Penggambaran karakter atau pertokohan dalam komik dianggap krusial. Mereka berperan penting dalam menjalin dan mengkoordinasi plot cerita. Menurut McCloud, ada tiga kualitas dalam pembentukan karakter: 1) Kehidupan diri, yakni latar belakang sejarah dan kemauannya, 2) Perbedaan visual, adalah ciri wajah, badan dan pakaian yang khusus dan mudah diingat, dan 3) Pembawaan ekspresi, yaitu kebiasaan cara bicara dan tingkah lakunya. (McCloud, 1993:71)

\section{Metode Penelitian}

Oleh karena relief Kresnayana berada di Candi Prambanan sehingga keberadaannya masih dapat dilacak dengan pasti. Dengan begitu, obervasi langsung dilakukan untuk mengetahui langsung relief tersebut ditempatnya. Studi pustaka dan dokumentasi juga perlu guna mendapat data-data penting dan teori komik yang dapat diacu.

\section{Hasil dan Pembahasan}

Candi Wisnu merupakan salah satu candi di kompleks Candi Roro Jonggrang Yogyakarta. Candi ini termasuk dalam tiga candi utama, posisinya berada di samping utara/kanan Candi Siwa (tengah). Kompleks candi tersebut mulai dibangun pada masa Dinasti Sanjaya sekitar tahun $825 \mathrm{M}$, dan selesai pada $856 \mathrm{M}$. Kemudian ditemukan oleh G. A. Lons pada tahun 1733 dalam kondisi berantakan. Sesudah itu, dilakukan pembinaan beberapa kali berturut-turut oleh para arkeolog dari dalam dan luar negeri. Akhirnya, pada bulan April 1991 diresmikan oleh Presiden RI. 


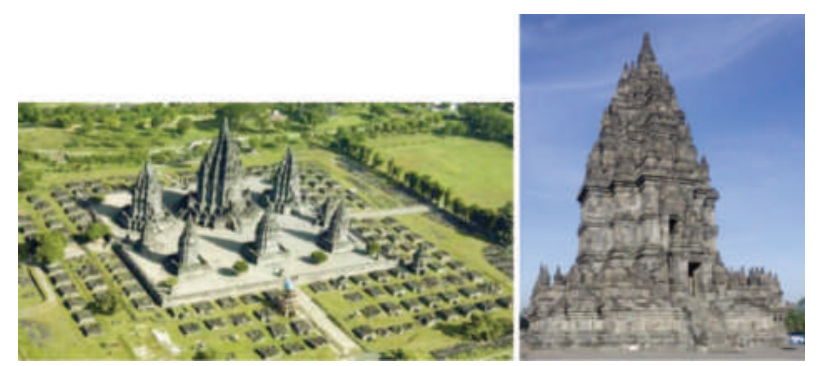

Gb. 3. Kompleks candi Roro Jonggrang di Prambanan dan Candi Wisnu (tampak dari timur)

(Sumber foto: www.jogja.co, diunduh 19:50 23/02/2017 dan Crisco 1492)

Keadaan relief Kresnayana di Candi Wisnu masih cukup baik saat ini. Secara keseluruhan, hampir semua panel dapat dilihat dengan jelas dan detil. Kondisi beberapa panel memang ada yang tidak bagus. Sebagian cuil, retak dan terkikis, yang lainnya ada yang tidak utuh. Menurut Moertjipto dan Bambang Prasetya, ketigapuluh panel tersebut masih dibagi dalam beberapa adegan. (Moertjipto dan Prasetya, 1997: 12)

Relief tersebut berada di dinding bagian dalam pagar balkon/langkan candi. Cara membaca relief Kresnayana adalah dimulai dari selatan pintu masuk candi. Dibaca menuju ke kanan atau searah dengan putaran jarum jam sehingga berakhir di sebelah kiri pintu masuk. Cara baca ini sesuai dengan pradaksina.

\section{Panel-panel Relief}

Di bawah ini adalah tiga dari 30 panel yang dapat ditunjukkan di sini. Semuanya memiliki adegan dan deskripsi yang sesuai dalam buku "The Kresnayana Reliefs of The Visnu Temple".

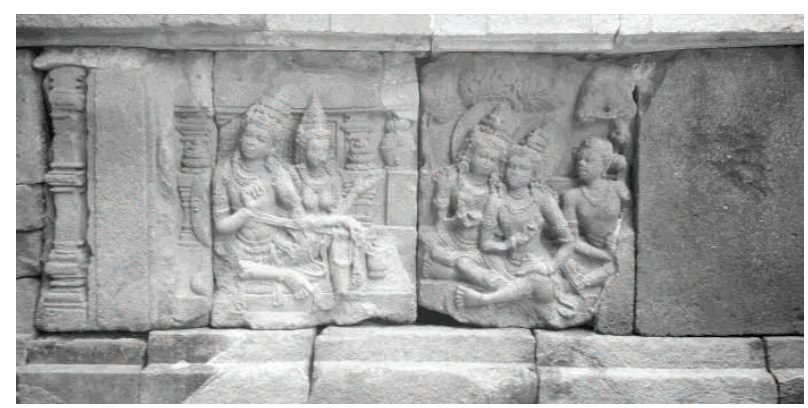

Gb. 4. Panel 1

(Sumber gambar: dokumentasi Yohanes Sambodo)
Adegan pertama: pertemuan di kerajaan Mathura, yang diadakan Raja Ugrasena, dihadiri oleh istrinya dan kerabat kerajaan. Adegan kedua: sebagian relief hilang; tinggal bagian belakang yang tampak, seekor gajah dan kepala kuda.

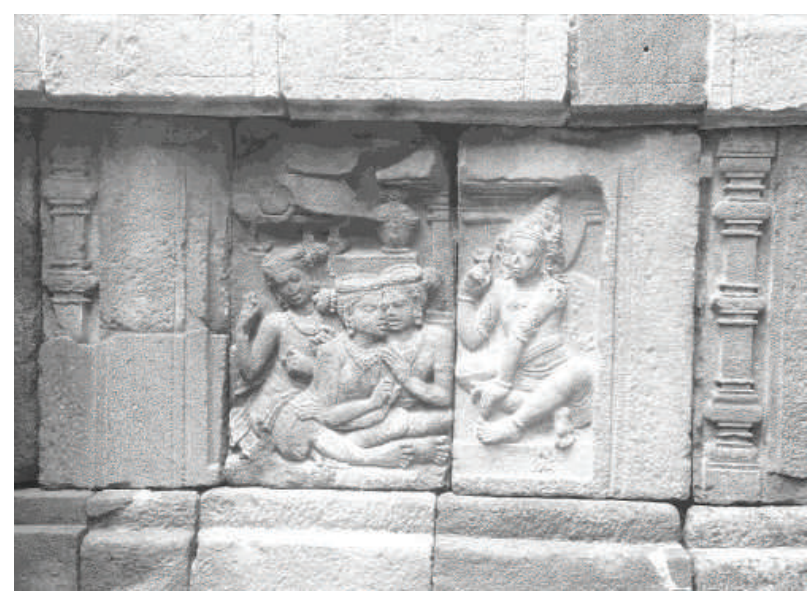

Gb. 5. Panel 2 Adegan: Raja Ugrasena dihadapan kedua istrinya di kerajaan Mathura.

(Sumber gambar: dokumentasi Yohanes Sambodo)

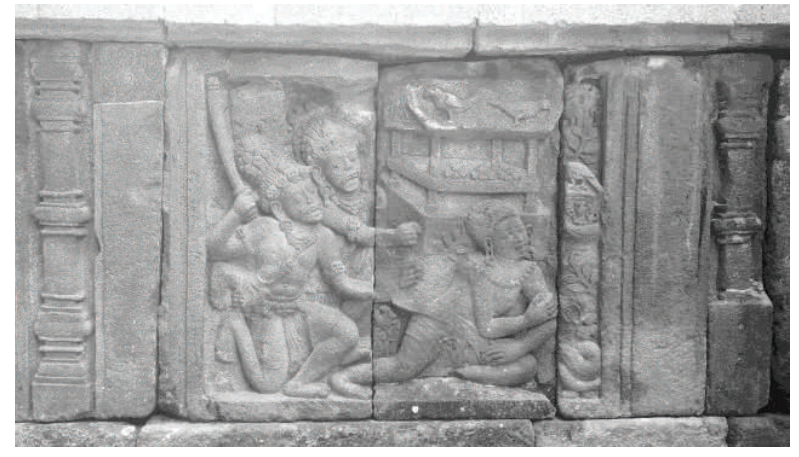

Gb. 6. Panel 3

(Sumber gambar: dokumentasi Yohanes Sambodo)

Adegan: Kamsa berusaha membunuh Dewaki, tetapi dihalangi oleh Wasudewa.

\section{Pembahasan}

Dalam pembahasan ini, semua panel relief akan digambar ulang menjadi hitam putih dua dimensional. Hal ini dimaksudkan untuk: 1) Membedakan penelitian seni rupa dengan disiplin ilmu yang lain. 2) Mengusahakan supaya rupa relief menjadi lebih dapat dicermati, oleh karena antisipasi penyetakan gambar foto tidak terlalu tajam. Semua panel diwujudkan dengan garis yang berupa kontur pada objek-objeknya dan 
arsiran pada wilayah bayangan. 3) Mendasarkan visualisasi pada komik modern yang umumnya diciptakan dengan medium pena, tinta dan kertas.

\section{Uraian Panel-panel}

Panel 1. Relief Kresnayana merupakan komik yang tidak berisi kata-kata dan penggambaran isi semua panelnya dibagi menjadi pecahan-pecahan. Panel-panel relief Kresnayana ter-jukstaposisi pada tembok dalam turutan yang sesuai dengan pradaksina.

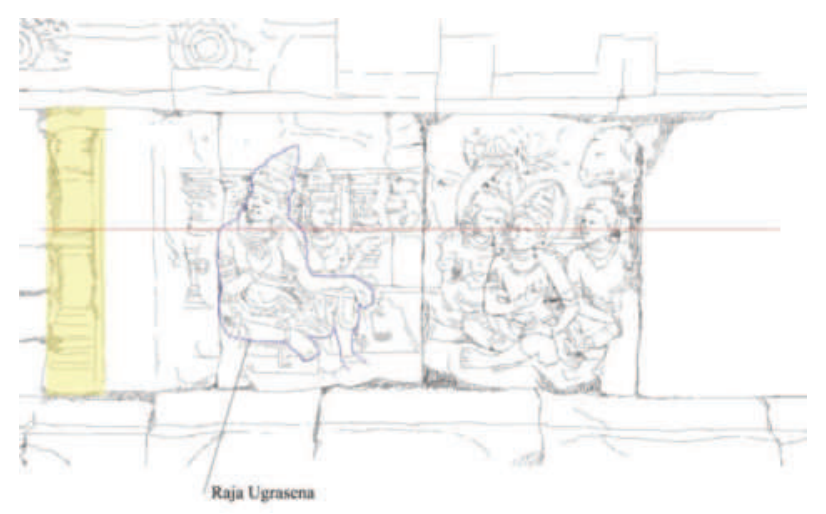

Gb. 7. Panel 1 hitam-putih

(Sumber gambar: dokumentasu Yohanes Priambodo)

Panel 2. Panel ini memiliki dua adegan yang dibagi menjadi empat pecahan kecil. Pecahan pertama berada di paling kiri yang ada pilarnya, kemudian kedua dan ketiga berisi banyak tokoh, serta di paling kanan pecahan batu polos. Keempat pecahan kecil tersebut menjadi satu tema. Sebenarnya masih ada satu adegan lagi, yaitu adanya kepala gajah yang berada dipojok kanan atas dalam pecahan batu ketiga. Relief pada pecahan batu keempat, sebelah kanan telah hilang dan diganti blok batu polos.

Pertokohan. Semua tokoh di dalam panel diwujudkan hampir sama semua antara raja dan kerabatnya, antara pria dan wanita. Namun dengan gestur, pakaian dan aksesori yang berbeda, mereka dapat dibedakan menurut tiga unsur tersebut. Selain itu, kalau dicermati, faktor pembeda pada tokoh-tokoh itu juga ada pada telinga mereka. Telinga masing-masing tokoh diberi semacam anting (suweng, bahasa Jawa) yang bentuknya tidak sama. Raja ditempatkan paling kiri duduk pada singgasananya, diikuti istrinya yang dibelakangnya. Ketiga kerabat mereka sedang duduk dalam panel kedua. Perlu diketahui pula, Raja Ugrasena dan istrinya berada di posisi yang lebih tinggi dibanding kerabatnya. Ini berarti keluarga raja berkedudukan atau berstatus di atas bawahannya. Aksesori yang dipakai masing-masing tokoh juga hampir sama. Keempat tokoh memakai mahkota (tropong; istilah Jawa dalam wayang orang), tetapi berbedabeda bentuknya. Anting/suweng dipakai oleh semuanya, namun pada tokoh urutan pertama dari kanan antingnya tidak sebesar keempat tokoh lain. Mereka juga memakai kalung, Klat bahu (bahasa Jawa; semacam gelang yang dipakai pada lengan atas), gelang, sabuk, celana pendek (kathok; bahasa Jawa), dan kroncong (bahasa Jawa untuk gelang kaki dalam wayang orang). Raja Ugrasena juga memakai sampur (bahasa Jawa untuk selendang) yang terurai ke bawah.

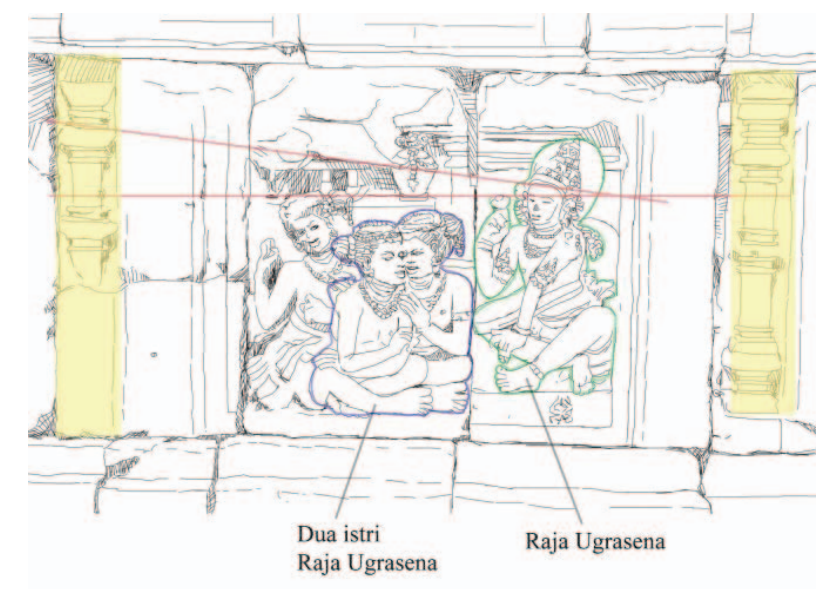

Gb. 8. Panel 2 hitam-putih

(Sumber gambar: dokumentasi Yohanes Priambodo)

Komposisi dalam Panel. Pembagian bidang yang sama lebar menjadikan komposisinya seimbang. Namun, kalau dirasakan, panel kecil kedua lebih berat dibanding panel kecil pertama, oleh karena figur dalam panel kedua lebih banyak dan memiliki intensitas gelap lebih rendah. Wajah-wajah mereka juga termasuk faktor komposisi. Ada tiga tokoh wajahnya menghadap ke kiri dan dua tokoh menghadap ke kanan. Keseluruhan penggambaran wajah jika dirasakan akan terasa berat ke Pertokohan, Pecahan pertama dari kiri berisi Kamsa yang membawa pentungan, belakangnya ialah Wasudewa. Pada pecahan selanjutnya terdapat tokoh yang 
bernama Dewaki digambarkan tersungkur. Ada dua burung dalam pecahan tengah. Pecahan terakhir menggambarkan sebagian kecil latar belakang, yaitu diisi burung, ular dan tumbuhan, sebelah kiri. Tiga tokoh tersebut seperti sedang memandang pilar di sebelah kiri.

Panel 3. Panel ini memliki satu adegan yang dibagi dalam dua pecahan kecil. Diapit oleh dua pilar, tetapi pilar sebelah kiri sudah rompal pada bagian bawah dan telah ditambal dengan batu.

Pertokohan. Raja Ugrasena ditempatkan sebelah kanan, kedua istrinya di tengah dan satu pelayan wanita berada di kiri. Raja menduduki posisi lebih tinggi daripada ketiga wanita itu. Perlu diketahui, adanya ketiga tokoh itu mengikat rambut mereka serta dua di antaranya adalah istri raja, ini berarti ketiganya berjenis kelamin wanita. Namun, mereka tidak memakai baju tetapi hanya memakai celana. Ketiga tokoh dalam panel ini duduk bersila, sedangkan satu tokoh di kiri tidak nampak bersila. Raja memakai aksesori cukup lengkap mulai dari kepala sampai kaki. Busana ketiga wanita itu hampir sama. Mahkota masih dipakai oleh raja, namun ketiga wanita memakai semacam ronce bunga yang ditaruh di atas rambut. Masing-masing memasang suweng pula yang bentuknya beda-beda, tetapi kalung mereka hampir sama. Hanya raja yang memakai kroncong di pergelangan kakinya. Raja juga membawa bunga di tangan kanannya. Selain itu, raja memiliki tanda khusus di sekitar kepalanya, yaitu halo. Halo melambangkan kesucian dan kebaikan orang-orang suci tersebut, dan menutupi segala kekurangan yang mungkin ada pada mereka. Bentuknya memang tidak bulat sempurna.

Komposisi dalam Panel. Panel ini memiliki komposisi asimetris sehingga terasa tidak seimbang dan dinamis. Tiga tokoh dan adanya tempayan serta pendapa yang berada pada pecahan sebelah kiri menjadi pemberat. Apalagi sang raja berada di kanan dan menempati letak lebih ke atas, jadi seperti melayang. Ini pun yang meringankan wilayah panel sebelah kanan. Nada gelap terang juga lebih kuat dalam panel sebelah kiri dibanding sebelah kanan.

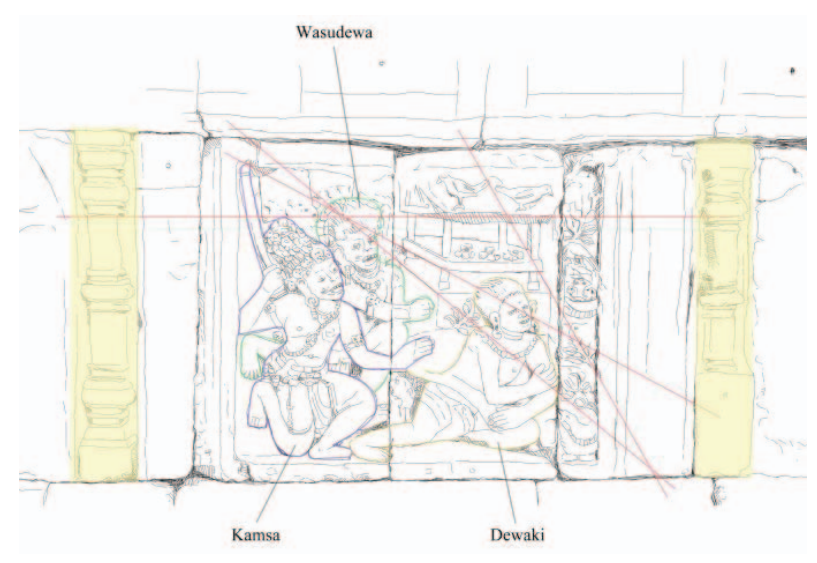

Gb. 9. Panel 3 hitam-putih (Sumber gambar: dokumentasi Yohanes Sambodo)

Panel 4. Relief ketiga berpanel tiga. Panel ini hanya menceritakan satu adegan. Ketiga panel itu ukurannya hampir sama. Panel paling kanan bergabung dengan pilar. Kamsa memakai aksesori cukup beragam. Bando dari rangkaian bentuk tengkorak-tengkorak dipakai di kepalanya. Tengkorak ini adalah lambang kematian dan nafsu jahat. Dia masih memakai kalung, suweng, namun ada semacam tali kalung yang 14, menggantung dari lehernya ke bagian perut (ulur-ulur, sebutan bahasa Jawa dalam aksesori wayang kulit). Di tangannya hanya memakai klat bahu dengan tanda tengkorak juga. Dia tidak mengenakan celana melainkan jarit yang diikat dengan sabuk. Dia juga membawa semacam pentungan di tangan kanannya yang akan digunakannya untuk membunuh Dewaki. Pentungan itu bukan pedang, perhatikan bagian atas senjata tersebut; ada dua setrip paralel yang tidak ada dalam sebuah pedang. Di belakang Kamsa ada Wasudewa yang tubuhnya tertutupi. Bisa dilihat aksesori yang dikenakan Wasudewa hanya ada di atas dahi, telinga, leher dan lengan atas tangan kanannya. Di atas dahinya ia kenakan sejenis bando yang disebut jamang (bahasa Jawa) yang juga ada dalam ragam aksesori wayang kulit. Dia juga memakai kalung di leher, suweng di telinga dan klat bahu di lengan tangan atasnya. Tokoh yang berada di pecahan tengah ialah Dewaki. Dia memakai busana yang sedikit dan hampir tanpa aksesori. Tidak ada aksesori apapun di kepalanya, kecuali suweng yang dipasang pada telinga. Dia mengenakan kalung yang berada di 
bawah leher karena terlihat kepanjangan atau berdiameter sangat lebar. Bukan celana yang dipakainya, melainkan jarit. Tangan kiri Dewaki memegang selendang.

Komposisi dalam Panel. Pada pecahan kiri, kedua tokoh mengisi hampir seluruh ruang pecahan. Pecahan tengah terisi penuh dan terasa berat pada bagian bawah. Dalam pecahan terakhir, isiannya hanya setengah lebar di sebelah kiri dari satu pecahan penuh. Komposisinya jika dirasakan masih seimbang meski tidak simetris. Ini disebabkan semua tokoh yang wajahnya menghadap ke kanan dan dua tokoh di pecahan kirilah yang mengimbanginya. Selain itu, separuh dari pecahan ketiga juga masih disertakan.

Sudut Pandang dan Perspektif. Sudut pandang dalam panel sebagian besar menggunakan eye level, lainnya bisa bird eye/mata burung

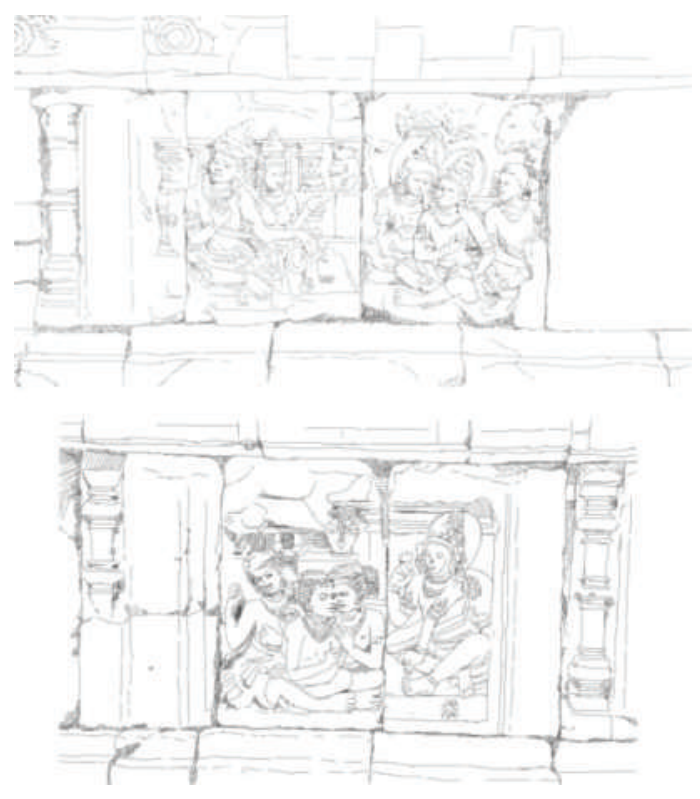

Gb. 10. Transisi dari panel 1 ke panel 2 (Sumber gambar: dokumentasi Yohanes Priambodo)

\section{Transisi Antarpanel}

\section{Panel 1 - Panel 2: Aksi ke aksi}

Dalam kedua panel di atas, satu tokoh yang selalu ada adalah raja Ugrasena. Tokoh tersebut hanya berpindah tempat. Kemudian tokoh lain dan latar belakangnya berubah. Dengan adanya satu tokoh yang tetap dan tanpa perubahan pose yang banyak dalam kedua panel itu, berarti transisi antarpanel ini adalah aksi ke aksi. ataupun lebih dari satu. Sudut pandang eye level menempatkan garis khayal horison di sekitar mata orang berdiri atau di sekitar pertengahan suatu bidang. Namun, batas-batas ruang panel atau bidangnya telah memengaruhi peletakan garis khayal tersebut. Beberapa panel sudah menunjukkan adanya perspektif walau tidak maksimal. Khususnya pada objek bangunan yang menjadi latar belakang. 15. Ada bangunan yang ditunjukkan datar ( lat), tetapi ada juga yang memakai perspektif. Penggunaan perspektif tentu berhubungan erat dengan sudut pandang. Hal ini maksudnya adalah perpaduan antara objek-objek yang mengisi latar depan/foreground dan latar belakang/background. Ketika satu panel dilihat dari unsur latar belakangnya, maka objek dalam latar depan akan mengikuti garis perspektif. Namun, bilamana dilihat dari unsur latar depan yang diisi dengan tokoh-tokoh, maka adanya perspektif jadi samar atau bahkan absen.
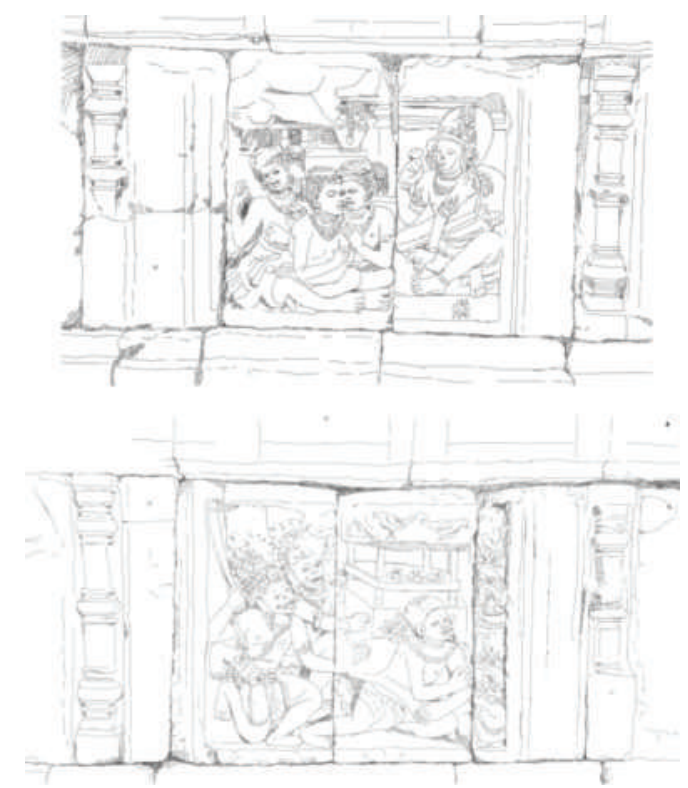

Gb. 11. Transisi dari panel 2 ke panel 3 (Sumber gambar: dokumentasi Yohanes Priambodo)

\section{Panel 2 - Panel 3: Adegan ke adegan}

Dua panel ini menunjukkan pergantian yang mendadak. Tokoh dan latar belakang berubah dengan drastis. Jika menurut deskripsi panel atau sinopsis, maka panel tiga berlatar di kerajaan sedangkan panel empat berlatar di perjalanan. Tokoh dalam panel tiga adalah raja Ugrasena dengan kedua istrinya, lalu panel empat berisi 
Kamsa, Wasudewa kemudian Dewaki. Transisi kedua panel ini termasuk adegan ke adegan.

\section{Kesimpulan}

Dapat ditegaskan kembali, bahwa ada kesamaan-kesamaan yang tampak jelas, namun ada pula ketidaksamaan yang dapat ditafsir. Unsur seperti panel, parit dan khususnya jukstaposisi telah menjadi kesamaan dalam relief Kresnayana dan komik. Selain bentuk visualisasinya, apapun yang berhubungan dengan kata-kata memang tidak dimiliki oleh relief tersebut. Dengan terungkapnya fakta-fakta dalam analisis, dapat disimpulkan bahwa relief Kresnayana di Candi Wisnu ternyata menunjukkan dan mempunyai ciri-ciri yang sama dengan komik. Sehingga relief tersebut teridentifikasi dengan 17 panel.

\section{Daftar Pustaka}

Bonneff, M. (1998). Komik indonesia. Jakarta: KPG.

McCloud, S. (1993). Understanding Comics: The Invisible Art Atau Memahami Komik. Jakarta: KPG.

Moertjipto. (1997). Kresnayana Reliefs of The Visnu Temple. Yogyakarta: Kanisius.

Moertjipto, \& Prasetya, B. (1997). The Kresnayana Reliefs of The Visnu Temple. Yogyakarta: Kanisius. 